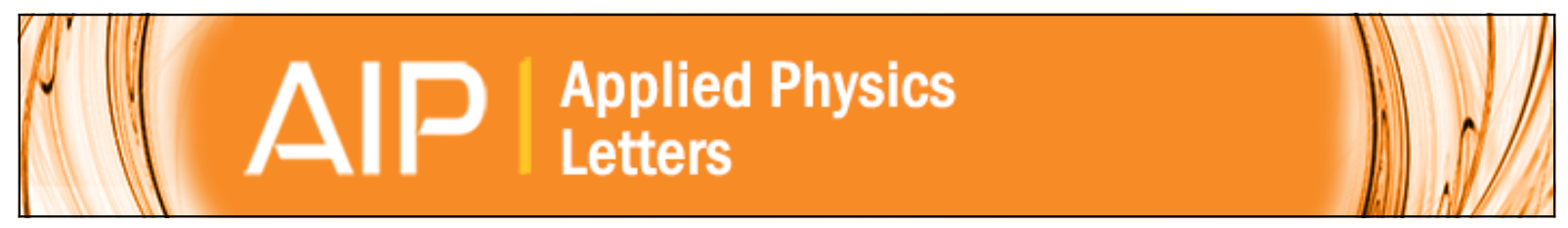

\title{
Deformation behavior of ion-beam-modified GaN
}

S. O. Kucheyev, J. E. Bradby, J. S. Williams, C. Jagadish, M. V. Swain, and G. Li

Citation: Applied Physics Letters 78, 156 (2001); doi: 10.1063/1.1335552

View online: http://dx.doi.org/10.1063/1.1335552

View Table of Contents: http://scitation.aip.org/content/aip/journal/apl/78/2?ver=pdfcov

Published by the AIP Publishing

\section{Articles you may be interested in}

Cross-sectional transmission electron microscopy observations of structural damage in $\mathrm{Al} 0.16 \mathrm{Ga} 0.84 \mathrm{~N}$ thin film under contact loading

J. Appl. Phys. 103, 033503 (2008); 10.1063/1.2836939

Mechanical properties of Al x Ga 1 - x N films with high Al composition grown on AIN/sapphire templates Appl. Phys. Lett. 91, 091905 (2007); 10.1063/1.2735551

Ion-beam-induced dissociation and bubble formation in GaN

Appl. Phys. Lett. 77, 3577 (2000); 10.1063/1.1330221

Ion-beam-induced porosity of GaN

Appl. Phys. Lett. 77, 1455 (2000); 10.1063/1.1290722

Elastic and plastic properties of GaN determined by nano-indentation of bulk crystal

Appl. Phys. Lett. 75, 2070 (1999); 10.1063/1.124919

\section{Model PS-100}

Tabletop Cryogenic Probe Station

\section{Lake Shore CRYOTRONICS}

\author{
An affordable solution for
} a wide range of research 


\title{
Deformation behavior of ion-beam-modified GaN
}

\author{
S. O. Kucheyev, a) J. E. Bradby, J. S. Williams, and C. Jagadish \\ Department of Electronic Materials Engineering, Research School of Physical Sciences \\ and Engineering, The Australian National University, Canberra, ACT 0200, Australia \\ M. V. Swain \\ Biomaterials Science Research Unit, Department of Mechanical and Mechatronis Engineering \\ and Faculty of Dentistry, The University of Sydney, Eveleigh, NSW 1430, Australia \\ G. Li \\ Ledex Corporation, No. 9, Ta-Yio First St., Ta-Fa Industrial District, Kaohsiung County, Taiwan, \\ Republic of China
}

(Received 31 July 2000; accepted for publication 31 October 2000)

\begin{abstract}
The deformation behavior of wurtzite $\mathrm{GaN}$ films modified by ion bombardment is studied by nanoindentation with a spherical indenter. Results show that implantation disorder significantly changes the mechanical properties of GaN. In particular, GaN amorphized by ion bombardment exhibits plastic deformation even for very low loads with dramatically reduced values of hardness and Young's modulus compared to the values of as-grown GaN. Implantation-produced defects in crystalline GaN suppress the plastic component of deformation and significantly change the values of hardness and Young's modulus. In addition, implantation disorder in crystalline GaN suppresses both "pop-in" events during loading and the appearance of slip traces on the sample surface as a result of indentation. This strongly suggests that slip nucleation (rather than a phase transformation) is the physical mechanism responsible for the pop-in events observed during loading of as-grown crystalline GaN. (C) 2001 American Institute of Physics. [DOI: 10.1063/1.1335552]
\end{abstract}

Gallium nitride is currently the subject of intensive research because of the very important technological applications of this material. ${ }^{1}$ Several studies of the mechanical properties of as-grown $\mathrm{GaN}$ have been reported in the literature. ${ }^{2-8}$ However, to our knowledge, the effects of implantation damage on the deformation behavior of $\mathrm{GaN}$ have not yet been studied. This is not surprising since damage processes in $\mathrm{GaN}$ exposed to ion bombardment are still not well documented in the literature. However, understanding the deformation behavior of ion-beam-modified $\mathrm{GaN}$ is not only important for contact damage issues in the GaN industry but is also necessary for understanding the evolution of the structural characteristics of $\mathrm{GaN}$ under ion bombardment. ${ }^{9}$

In this letter, we present results on the mechanical properties of (i) crystalline GaN with a relatively high concentration of implantation-produced defects and (ii) GaN amorphized by ion bombardment. Results show that, unlike the situation for $\mathrm{Si},{ }^{10}$ implantation damage dramatically changes the deformation behavior of GaN.

A $\sim 2 \mu \mathrm{m}$ thick wurtzite undoped $\mathrm{GaN}$ epilayer was grown on a $c$-plane sapphire substrate by metalorganic chemical vapor deposition in a rotating disk reactor at Ledex Corporation. All samples used in this study were cut from the same GaN wafer. For this indentation study, two samples were modified by ion bombardment - a GaN sample with implantation-produced defects (referred below as "iondamaged" GaN) and GaN amorphized by ion implantation. All implants were done using the Australian National University (ANU) 1.7 MV tandem accelerator (NEC, 5SDH).

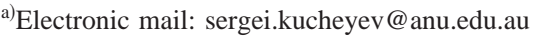

To prepare an amorphous layer, GaN was bombarded with $2 \mathrm{MeV}{ }^{197} \mathrm{Au}^{+}$ions at liquid nitrogen temperature with a beam flux of $5 \times 10^{12} \mathrm{~cm}^{-2} \mathrm{~s}^{-1}$ to a dose of 1.5 $\times 10^{16} \mathrm{~cm}^{-2}$. Such implantation results in the formation of a $\sim 0.6 \mu \mathrm{m}$ thick, completely amorphous surface layer, as discussed in detail elsewhere. ${ }^{11}$ It should be noted that GaN amorphized by ion bombardment exhibits some degree of porosity, ${ }^{11}$ which may also affect the deformation behavior of amorphized GaN discussed below.

The ion-damaged sample, with a relatively high concentration of implantation-produced defects (but not amorphous), was prepared by multiple-energy bombardment with ${ }^{197} \mathrm{Au}$ ions at $300{ }^{\circ} \mathrm{C}$. The implant conditions to prepare this sample are given in Table I. Given the present understanding of ion-beam-damage processes in $\mathrm{GaN}$, such multiple-energy implantation at an elevated temperature results in the formation of lattice defects, including some planar defects, in the implanted layer (up to $\sim 1 \mu \mathrm{m}$ from the surface). ${ }^{9}$ It should be noted that, for the ion doses used in this study, the concentration of implanted Au species $(<0.06$ at. \%) is expected to have a negligible effect on the mechanical properties of $\mathrm{GaN}$. Rather, the deformation behavior of ion-beammodified $\mathrm{GaN}$ should be determined by implantation-

TABLE I. The implant conditions used to prepare the ion-damaged sample by multiple-energy bombardment with ${ }^{197} \mathrm{Au}$ ions at $300{ }^{\circ} \mathrm{C}$.

\begin{tabular}{lcc}
\hline \hline $\begin{array}{c}\text { Energy } \\
(\mathrm{MeV})\end{array}$ & $\begin{array}{c}\text { Dose } \\
\left(10^{14} \mathrm{~cm}^{-2}\right)\end{array}$ & $\begin{array}{c}\text { Beam flux } \\
\left(10^{12} \mathrm{~cm}^{-2} \mathrm{~s}^{-1}\right)\end{array}$ \\
\hline 6.6 & 5 & 5.2 \\
2 & 7 & 18 \\
0.45 & 3 & 17 \\
\hline \hline
\end{tabular}




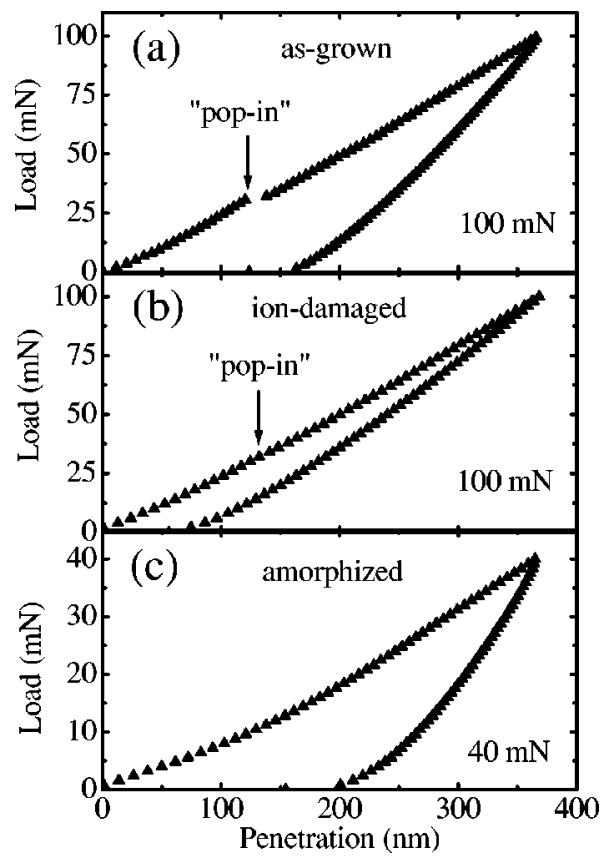

FIG. 1. Typical continuous load-unload curves of (a) as-grown, (b) iondamaged, and (c) amorphized GaN films. Note that the maximum load is $100 \mathrm{mN}$ for (a) and (b) and is $40 \mathrm{mN}$ for (c).

produced lattice disorder and its consequences.

As-grown and implanted $\mathrm{GaN}$ films were subjected to indentation using an ANU UMIS-2000 nanoindentation system with an $\sim 4.2 \mu \mathrm{m}$ radius spherical indenter. The shape of the indenter tip was characterized by scanning electron microscopy. The indentation system and indenter tip were carefully calibrated by indenting fused silica. A series of both partial and continuous load-unload indents was carried out on each of the above three $\mathrm{GaN}$ samples at loads up to 100 $\mathrm{mN}$ (in the case of as-grown and ion-damaged $\mathrm{GaN}$ ) and up to $40 \mathrm{mN}$ (in the case of amorphized $\mathrm{GaN}$ ). All indents were performed at room temperature. The load-unload data was analyzed using the method of Field and Swain ${ }^{12}$ to extract the hardness and elastic modulus as a function of indenter penetration.

After indentation, residual impressions of all indents were examined by tapping mode atomic force microscopy (AFM) to check for the evidence of slip, cracking, and pileup/sink-in. ${ }^{13}$ The AFM study was performed under ambient conditions with a Nanoscope III scanning probe microscope using commercial single-beam $\mathrm{Si}$ cantilevers with force constants of $30-120 \mathrm{Nm}^{-1}$.

Figure 1 shows typical continuous load-unload forcedisplacement curves of as-grown [Fig. 1(a)], ion-damaged [Fig. 1(b)], and amorphized [Fig. 1(c)] GaN films. Figure 1(a) clearly illustrates a discontinuity (or pop-in) of the yield response occurred during loading of as-grown GaN. This result is in agreement with nanoindentation data previously reported for GaN. ${ }^{3,6,8}$ Interestingly, Fig. 1(b) reveals that in ion-damaged $\mathrm{GaN}$, the pop-in event is still present but significantly less pronounced than in as-grown GaN. Finally, Fig. 1(c) shows no discontinuities in the load-displacement curve of amorphous $\mathrm{GaN}$, in full agreement with the expected deformation behavior of an amorphous solid. ${ }^{10}$

Shown in Fig. 2 are typical amplitude-mode AFM images of as-grown [Fig. 2(a)] and ion-damaged [Fig. 2(b)]

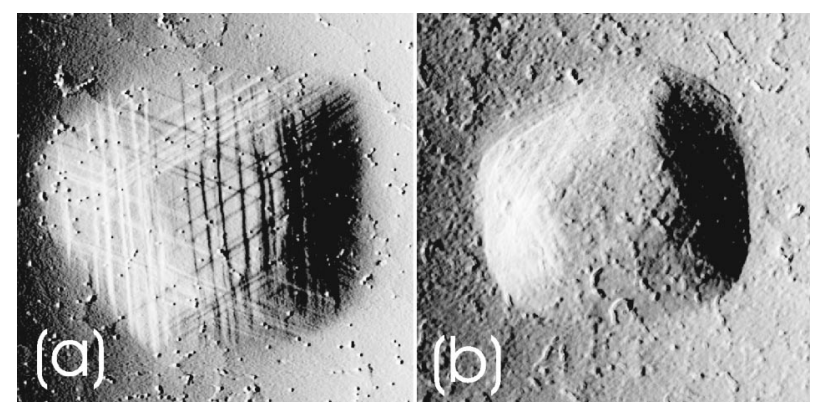

FIG. 2. Typical amplitude-mode AFM images of (a) as-grown and (b) iondamaged $\mathrm{GaN}$ films indented at a maximum load of $100 \mathrm{mN}$. [Horizontal field width $=4 \mu \mathrm{m}$ for both images (a) and (b).]

GaN films indented at a maximum load of $100 \mathrm{mN}$. These AFM images clearly illustrate that slip, which occurs during loading of as-grown $\mathrm{GaN}$, is strongly suppressed in iondamaged GaN. A comparison of nanoindentation data [see Figs. 1(a) and 1(b)] and AFM data (see Fig. 2) gives a compelling argument that slip nucleation (rather than a phase transformation) is the physical mechanism responsible for the pop-in events observed during loading of GaN. Therefore, the deformation behavior of $\mathrm{GaN}$ is somewhat similar to that of sapphire. ${ }^{14}$

Shown in Fig. 3 are the curves of the average contact pressure [or (Meyer) hardness] $H$ [Fig. 3(a)] and Young's modulus $E$ [Fig. 3(b)] as a function of indenter penetration below the circle of contact, as determined from the partial load-unload data. This figure, showing data for as-grown, ion-damaged, and amorphized GaN, reveals that ion bombardment dramatically modifies $H$ and $E$. It is seen that, for shallow penetration depths of the indenter (prior to the pop-in event), the $H$ and $E$ values of ion-damaged $\mathrm{GaN}$ are

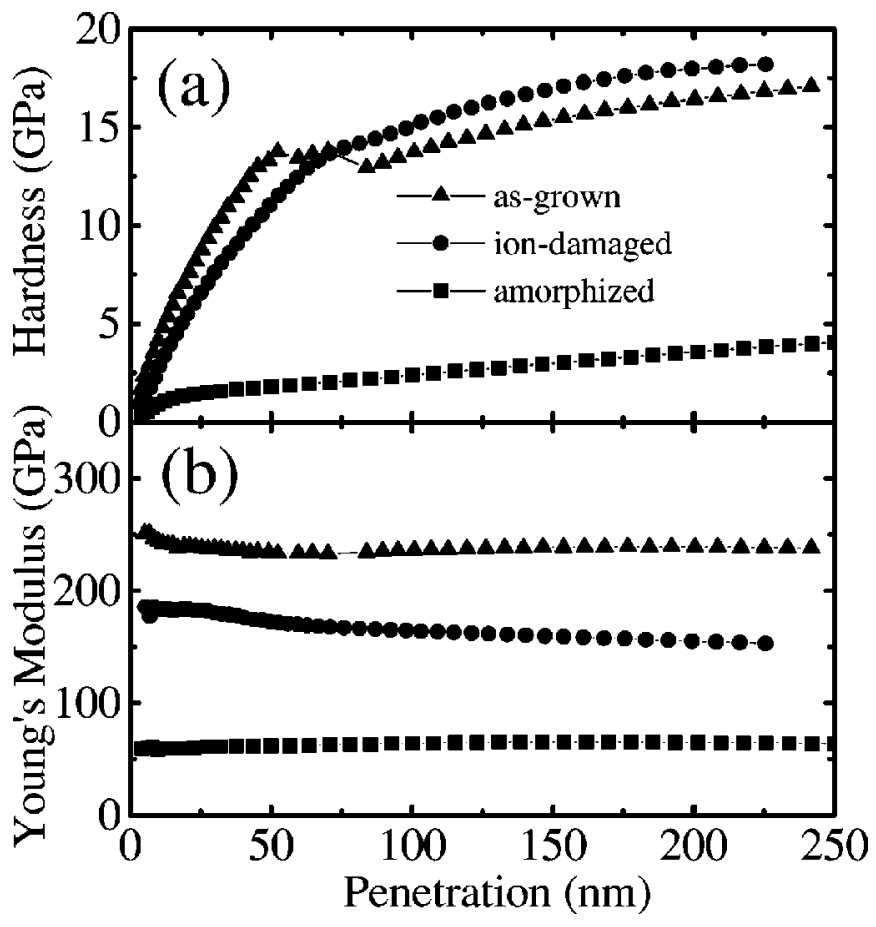

FIG. 3. The curves of (a) the hardness and (b) Young's modulus as a function of indenter penetration below the circle of contact, as determined from the partial load--unload data. Figures show data for as-grown, iondamaged, and amorphized GaN, as indicated in the legend in (a). 
TABLE II. The values of hardness $H$ and Young's modulus $E$ at a plastic penetration depth of $100 \mathrm{~nm}$ for the three $\mathrm{GaN}$ samples used in this study.

\begin{tabular}{lcc}
\hline \hline GaN sample & $\mathrm{H}(\mathrm{GPa})$ & $\mathrm{E}(\mathrm{GPa})$ \\
\hline as-grown & 13.4 & 233 \\
ion-damaged & 15.1 & 164 \\
amorphized & 2.4 & 65 \\
\hline \hline
\end{tabular}

lower than those of as-grown material. As expected, the value of $E$ is not affected by slip and remains essentially constant for the whole indenter penetration depth. ${ }^{15}$ However, slip significantly affects $H$ of as-grown GaN, while in ion-damaged GaN slip is strongly suppressed, and, for larger depths of indenter penetration, $H$ becomes larger than that of as-grown GaN. Figure 3 also shows that the values of $H$ and $E$ of amorphized GaN are significantly lower than those of as-grown and ion-damaged $\mathrm{GaN}$; i.e., amorphous $\mathrm{GaN}$ is very soft. Table II gives the values of $H$ and $E$ for the three GaN samples used in this study at a plastic penetration depth of $100 \mathrm{~nm}$, a depth where the substrate effects are expected to be small.

Finally, a close examination of partial load-unload curves reveals that in ion-damaged GaN the purely elastic regime extends to higher loads and penetration depths than in as-grown GaN. This result indicates that implantation disorder in crystalline $\mathrm{GaN}$ somewhat suppresses pressureinduced nucleation and/or propagation of extended defects, the processes which are most likely responsible for the plastic deformation of crystalline GaN. ${ }^{7,8}$ In contrast, in amorphized $\mathrm{GaN}$, deformation response is elastic-plastic even for very low loads, and, with increasing load, plastic deformation dominates with pileup around the impression (as revealed by AFM), typical for indentation of amorphous solids. Such a difference in the deformation modes of as-grown, ion-damaged, and amorphized $\mathrm{GaN}$ is also reflected by the depths of residual depression (see Figs. 1 and 2) and the depths of maximum plastic penetration (see Fig. 3) of the above three samples.

In conclusion, wurtzite GaN films modified by ion bombardment have been studied by nanoindentation with a spherical indenter. Implantation-produced defects suppress both pop-in events and slip during loading. This result suggests that slip nucleation (rather than a phase transformation) is responsible for pop-in events. In addition to suppressing slip, implantation disorder in crystalline $\mathrm{GaN}$ also suppresses the plastic component of deformation, which may suggest that slip is the major contributor to the plastic component of deformation of crystalline GaN. The deformation behavior of amorphous $\mathrm{GaN}$ is very different from that of as-grown crystalline GaN. In particular, amorphous GaN exhibits plastic flow even for very low loads. In addition, the values of hardness and elastic modulus of amorphous GaN are much lower than those of as-grown GaN, as indicated in Table II. Finally, this study may have significant technological implications for the estimation of contact damage in ion-beam-processed $\mathrm{GaN}$.

${ }^{1}$ See, for example, a recent review S. J. Pearton, J. C. Zolper, R. J. Shul, and F. Ren, J. Appl. Phys. 86, 1 (1999), and references therein.

${ }^{2}$ M. D. Drory, J. W. Ager III, T. Suski, I. Grzegory, and S. Porowski, Appl. Phys. Lett. 69, 4044 (1996).

${ }^{3}$ G. Yu, H. Ishikawa, T. Egawa, T. Soga, J. Watanabe, T. Jimbo, and M. Umeno, J. Cryst. Growth 189/190, 701 (1998).

${ }^{4}$ I. Yonenaga, T. Hoshi, and A. Usui, Mater. Res. Soc. Symp. Proc. 595, W3.901 (1999).

${ }^{5}$ R. Nowak, M. Pessa, M. Suganuma, M. Leszczynski, I. Grzegory, S. Porowski, and F. Yoshida, Appl. Phys. Lett. 75, 2070 (1999).

${ }^{6}$ D. Cáceres, I. Vergara, R. González, E. Monroy, F. Calle, E. Muñoz, and F. Omnés, J. Appl. Phys. 86, 6773 (1999).

${ }^{7}$ M. H. Hong, A. V. Samant, V. Orlov, B. Farber, C. Kisielowski, and P. Pirouz, Mater. Res. Soc. Symp. Proc. 572, 369 (1999); M. H. Hong, P. Pirouz, P. M. Tavernier, and D. R. Clarke, ibid. 622 (in press).

${ }^{8}$ S. O. Kucheyev, J. E. Bradby, J. S. Williams, C. Jagadish, M. Toth, M. R. Phillips, and M. V. Swain, Appl. Phys. Lett. 77, 3373 (2000).

${ }^{9}$ S. O. Kucheyev, J. S. Williams, C. Jagadish, J. Zou, and G. Li, Phys. Rev. B 62, 7510 (2000); S. O. Kucheyev, J. S. Williams, J. Zou, C. Jagadish, and G. Li, Nucl. Instrum. Methods Phys. Res. B (in press).

${ }^{10}$ J. S. Williams, Y. Chen, J. Wong-Leung, A. Kerr, and M. V. Swain, J. Mater. Res. 14, 2338 (1999).

${ }^{11}$ S. O. Kucheyev, J. S. Williams, C. Jagadish, J. Zou, V. S. J. Craig, and G. Li, Appl. Phys. Lett. 77, 1455 (2000).

${ }^{12}$ J. S. Field and M. V. Swain, J. Mater. Res. 8, 297 (1993).

${ }^{13}$ G. M. Pharr, Mater. Sci. Eng., A 253, 151 (1998).

${ }^{14}$ R. Nowak, C. L. Li, and M. V. Swain, Mater. Sci. Eng., A 253, 167 (1998).

${ }^{15}$ Slightly nonconstant behavior for $E$ of ion-damaged $\mathrm{GaN}$ with increasing penetration depth [see Fig. 3(b)] may be attributed to a nonuniform distribution of implantation disorder and/or to the substrate effect. 